Supporting Information for

\title{
Anion Chelation by Amido Acid-functionalized Fused Quartz/Water Interfaces Studied by Nonlinear Optics
}

\author{
Julianne M. Gibbs-Davis, Patrick L. Hayes, Karl A. Scheidt, Franz M. Geiger* \\ Department of Chemistry and Institute for Nanotechnology, Northwestern University, \\ 2145 Sheridan Road, Evanston, Illinois 60208-3113, USA
}

SHG intensity response of $\mathrm{Cr}(\mathrm{VI})$ interacting with a butylamide-modified surface that is chemically identical to the GABA surface except for the substitution of the carboxylic acid group by a methyl group. The SHG signal intensity shows no appreciable increase when chromate (up to $1.3 \times 10^{-4} \mathrm{M}$ ) is added to the aqueous phase and flowed across the interface, suggesting that the chromate is not interacting efficiently with the butylamidemodified surface.

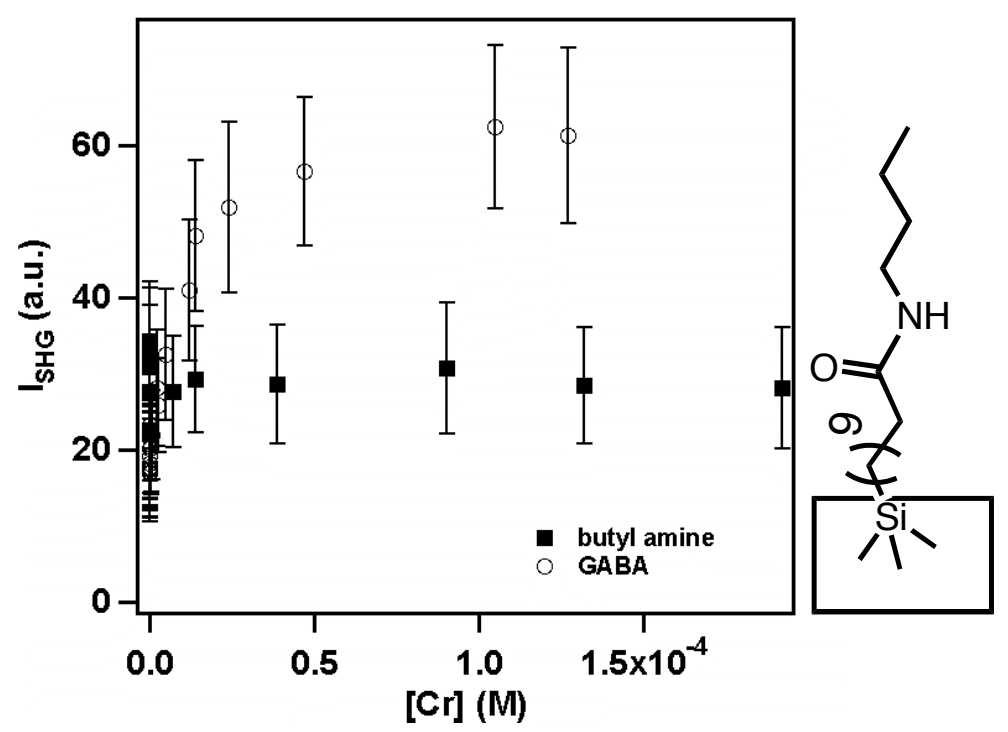

Fig. S1: SHG intensity as a function of $\mathrm{Cr}(\mathrm{VI})$ bulk solution concentration ( $\mathrm{pH}$ 7) for $\mathrm{Cr}(\mathrm{VI})$ interacting with a butylamide-modified surface (filled squares) and GABA (empty circles). 